\title{
Knowledge, Attitude and Practice towards Novel Corona virus (COVID-19): A Cross-Sectional Study among Social Media Users in Nepal
}

\author{
Umesh Neupane1, Dirgha Raj Joshi², Puspa Raj Joshi ${ }^{3}$, Sanjay Chaudhary ${ }^{4}$, Lokeshwar
}

Chaurasia5, Laxmi Sha6, Shree Shyam Giri6

${ }^{1}$ Butwal Multiple Campus, Tribhuvan University, Butwal, Nepal

${ }^{2}$ Mahendra Ratna Campus Tahachal, Tribhuvan University \& Nepal Open University, Nepal

${ }^{3}$ Universal Center for Excellencein Research and Counselling (UCERC), Nepal

${ }^{4}$ Department of Surgery, Janaki Medical College, Tribhuvan University, Janakpur, Nepal.

${ }^{5}$ Department of Pharmacology, Janaki Medical College, Tribhuvan University, Janakpur, Nepal.

${ }^{6}$ Faculty, Sinha Health Foundation, Dhanusha, Janakpur

\section{ABSTRACT}

Background and Objectives: Public adherence to preventive measures like social distancing, lockdown, improved hygiene is influenced by their knowledge and attitude toward COVID-19. The effectiveness of those mitigation measures is highly dependent on the cooperation and compliance of all residents of the country. This study aims to assess the knowledge, attitude and practice of social media users with respect to six variables of socio-demographic parameters regarding the corona virus disease .

Material and methods: The cross-sectional study design was employed through an online survey. The data were collected from 218 respondents from April 15 to June 7, 2020 through Google Form. Frequency, percentage, Mann-Whitney U and Kruskal Wallis H Test were used to analyze the data.

Results: A high level of sensible knowledge regarding the overall knowledge (Mean=0.73, SD=0.11) about COVID-19 was observed. Participants have shown good sense of knowledge towards awareness (Mean=0.73, SD=0.14) and prevention (Mean=0.88, $\mathrm{SD}=0.15$ ) based knowledge as compared to the symptom (Mean=0.49, $\mathrm{SD}=0.19$ ) based knowledge. In response to attitude and practice, seven out of ten participants $(70.6 \%)$ believed that the country will succeed in controlling the virus. A good number of participants were wearing face masks (94.5\%), improving hygiene $(92.7 \%)$ and using sanitizer/soap (94\%). Around $91.7 \%$ of them were maintaining social distancing whereas $73.9 \%$ of participants think that the ongoing lockdown should be extended to control the transmission of virus. More dangerously, $42.7 \%$ of participants believed anti-malarial drugs are useful for treating the patients with COVID-19.

Conclusion: The present study revealed a good knowledge, optimistic attitude and appropriate practice among social media users towards COVID-19. The findings of this study might serve as the baseline for planning awareness campaigns to improve the knowledge, attitude and practice in some critical aspects to control the virus in public level, and implementing government efforts and plan for better containment of COVID-19.

Key words: COVID-19, social media, knowledge, attitude, practices

INTRODUCTION
The novel Corona virus (2019-nCoV, officially known as SARS-CoV-2 or COVID-19) was first 
reported in December 2019, as a cluster of acute respiratory illness in Wuhan, Hubei Province, China. Since then, it has been spreading rapidly to over 215 countries and has been declared a global pandemic by the World Health Organization (WHO) on $12^{\text {th March }} 2020$ [1]. To date, there are more than 8.9 million positive COVID-19 cases recorded with at least 466,848 deaths globally [2]. The COVID-19 is an enveloped non-segmented positive sense RNA virus [3]. Around six corona viruses have beenidentified to infect humans namely the $\alpha$ CoVs HCoV-229E, HCoV-NL63, $\beta$-CoVs HCoVHKU1 and HCoV-OC43 are responsible to cause mild respiratory symptoms similar to that associated with the common cold, while SARS-CoV-2, SARS-CoV, and MERS-CoV are implicated to cause lethal respiratory infections [4]. WHO classified the pandemic situation and spreading of coronavirus into four stages [5]. The first stage, Imported Cases, begins with the cases reported for the people who travelled in already affected areas. Whereas in the second stage, cases are reported in local level among family and friends, who came in contact with a person arriving from affected regions, called Local Transmission. In third the stage, transmission source becomes spread across the individual, who neither have any travel history nor came into contact with the affected person in the community called Community Transmission and is untraceable. The fourth stage is the worst of all and begins when the transmission becomes endemic and uncontrollable called Epidemic Transmission.

Nepal is a small landlocked country between China on the northern side and India in the east, west and south [6]. As soon as this catastrophic outbreak of COVID-19 has brought the worldwide threat to the living society, stringent measurement strategies were planned and implemented to confine the spread of COVID-19 in Nepal. In midJanuary, Nepal set up health-desk at the international airport and soon after suspended all international flights and vehicular movement on the long route [2]. The government declared the suspension of all classes and postponed all academic examinations. All Universities including Tribhuvan University, and Public Service Commission also postponed their examinations. Nepal dropped its highly advertised and widely expected tourism campaign Visit Nepal 2020 [2]. Finally, Lockdown measures were perceived as necessary to curb the spread of the virus as rapid human to human transmission [7].

The first case of COVID-19 in Nepal, also the first recorded case in South Asia, was detected on 23 January 2020 in a 32 years old Nepalese student based at Wuhan University of Technology, who had returned to Nepal [8]. Throat swab taken from the patient was sent to the WHO laboratory in Hongkong and confirmed to positive for COVID-19 using real-time RT-PCR assay. Between January and March, Nepal took steps to prevent a widespread outbreak of the disease while preparing for it by procuring essential supplies, equipment and medicine, upgrading health infrastructure, training medical personnel, and spreading public awareness. The first case of local transmission was confirmed on 4 April in Kailali District whereas the first death occurred on 14 May [9]. Since late January, 175,173 RT-PCR tests have been performed in 22 laboratories across the country, and262174rapid diagnostic tests (RDTs) have been carried out up to 21 June 2020 [10]. Although, the new cases have been continuing to be detected in different parts of the country and testing 
being increased, the modality of lockdown has been changed on 15 June, 2020 [11].
COVID-19 is a relatively new virus that has had devastating effects within a short time

Table 1: Questionnaire of knowledge and participant's responses towards COVID-19 (n=218)

Statements

Responses in percentage Mean SD

False True I Don't

Know

\section{A. Symptom-based knowledge}

1. The main clinical symptoms of COVID-19 are fever, fatigue, dry cough, and myalgia.

2. Unlike the common cold, stuffy nose, runny nose and sneezing are less common in persons infected with the COVID-19 virus.

3. Not all persons with COVID-19 will develop into severe cases. Only those who are elderly, have chronic illnesses and are obese are more likely to develop into severe cases.

4. Persons with COVID-19 cannot infect the virus to others when a fever is not present.

Total of symptoms based knowledge

\section{B. Awareness-based knowledge}

5. Is COVID-19 virus infection a life-threatening health issue?

6. Multi-organ failure is the cause of death of the patient suffering from COVID-19.

7. Eating or contacting wild animals would result in the infection by the COVID-19 virus.

8. The major means of human to human transmission of COVID-19 is through small droplets when infected people cough, sneeze or talk?

9. Currently, Nepal is in stage 2 of COVID-19 infection.

10. Anti-malarial drugs are being used for treating patients with COVID-19.

11. Currently, there is no effective cure for COVID-9, but early symptomatic and supportive treatment can help most patients recover from the infection.

12. Does quarantine mean a restriction on the movement of people that is intended to prevent the spread of disease?

13. Does isolation mean separating a sick individual with a contagious disease from healthy individuals?

14. Does lockdown mean an emergency protocol that usually prevents people from leaving an area?

15. Does social distancing mean actions intended to slow the spread of disease by minimizing close contact between individuals?

Total awareness-based knowledge

\section{Prevention-based knowledge}

16. It is not necessary for children and young adults to take measures to prevent infection by COVID-19 virus.

17. To prevent the infection by COVID-19, individuals should avoid going to crowded places such as train stations and also avoid taking public transportations.

18. Isolation and treatment of people who are infected with the COVID-19 virus are effective ways to reduce the spread of the virus.

19. Ordinary residents can wear general masks to prevent the infection by COVID-19 virus.

20. People who have contact with someone infected with the COVID-19 virus should be immediately isolated in a proper place. In general, the observation period is 14 days.

21. Does lockdown prevent human to human transmission of COVID-19?

Total of prevention based knowledge

$\begin{array}{lllll}1.8 & 96.3 & 1.8 & 0.96 & 0.18 \\ 29.4 & 57.3 & 13.3 & 0.41 & 0.49 \\ 30.7 & 61.5 & 7.8 & 0.61 & 0.49\end{array}$

80.3

10.19 .6

0.20

0.40

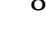

(2)

32.6

75.7

48.6

4.6

0.49

0.19

39.9

$38.1 \quad 22$

18.8

0.76

0.43

2.3

17.4

26.6

0.62

0.50

6.4

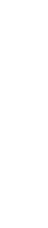

11.9

7.8

9.6

6.4

93.6

4.1

0.94

72.9

$42.7 \quad 30.7$

9.6

0.73

0.23

0.45

0.43

0.50

0.29

$85.8 \quad 2.3$

0.86

0.35

$89.4 \quad 2.8$

\begin{tabular}{lllll}
11 & 79.8 & 9.2 & 0.80 & 0.40 \\
& & & 0.88 & 0.15 \\
& & & 0.73 & 0.11 \\
\hline
\end{tabular}


since it was first detected in December 2019. The knowledge, attitudes and practices toward COVID-19 play an important rolein determining a society's readiness to accept behavioral change measures from health authorities. To date, there has been limited published data on population knowledge, attitudes and practices toward COVID-19, specifically in Nepal. It is therefore of utmost importance that the knowledge, attitudes and practices of the population need to be studied and make it critical for health authorities to plan appropriate strategies to prepare and manage the public. The main goal of the present study was to measure the level of knowledge, attitude, and practice concerning COVID-19, to detect socio-demographic variables associated with a satisfactory level of them and to explore awareness and health behaviors related to the prevention of Corona virus.

\section{MATERIAL AND METHODS}

The cross-sectional study design was adopted through an online survey. The link of the research instrument was shared through email, Facebook and Messengers. Age group, qualifications, geographical locations were not limited to the respondents and also our target was to rich 30 participants from each province.

Data Collection: The data were collected from $15^{\text {th }}$ April to $6^{\text {th }}$ June 2020 through Google Form. The self-constructed tool was implemented and the validity of the tool was ensured through the pre-test and views of related experts. All samples were chosen by Facebook friends and also request them to share the link with their friends. The survey was stopped by $7^{\text {th }}$ June 2020 .

Definition of Variables: Knowledge, attitudes and practices about COVID-19 were chosen as dependent variables; moreover, knowledge is categorized in three subsections as symptoms-based knowledge, awareness-based knowledge and preventionbased knowledgeon the basis of the nature of items. Knowledge was measured under three options as True, False and I don't know whereas attitudes were measured in threepoint ratings as agree, disagree and I don't know. COVID-19 related practices were measured under three categories as Yes, No and Not always.

Six confounding variables by means of age, gender, educational background, job role, location of residence and time of using social media per daywere used in the research.Age has four categories; less than 25 years (22.9\%), 26-35 years (43.1\%), 36-45 years (25.2\%) and more than 46 years $(8.7 \%)$, gender has two categories as male (21.1\%) and female (78.9\%), educational background is further categorized into six different streams; education (40.4\%), humanities (17.0\%), management (8.3\%), medical (10.1\%), science $(15.1 \%)$ and others (9.2\%) whereas others represent law, engineering, agriculture and school education. Similarly,there are three categories under job roles like teaching (62.4\%), private job (11.9\%) and students $(25.7 \%)$, participants were grouped under 7 provinces as per decentralized units of Nepal;Province 1 (13.8\%),Province 2 (13.8\%), Bagmati Province (14.7\%), Gandaki Province (14.2\%), Province 5 (15.6\%), KarnaliProvince (13.8\%) and Sudur-Paschim Province (14.2\%). Time of using social media has four categories as less than 3 hours (37.6\%), 3-6 hours (43.6\%), 6-9 hours (13.8\%) and more than 9 hours (5\%).

Statistical Analysis: Frequency and percentage were used under descriptive statistics. For mean and standard deviation 
(SD) calculation of each item, the scoring techniques were used as True- 1 , False- 0 and I don't know-0 for true statements however False-1, True- 0 and I don't know-0 for false statements. Additionally, the level of knowledge was determined as high or good (having mean greater than 0.5 ) and low or poor (having mean less than or equal to 0.05). Since normality was not assumed, MannWhitney U and Kruskal Wallis H Test [12] were adopted under inferential statistics to calculate the significant different having two and more than two categories, respectively, between the knowledge, attitude and practices with respect to all sociodemographic characteristics as age, gender, educational background, job role, location of residence, and time of using social media per day.

\section{RESULTS}

Table one shows that in comparison to awareness-based knowledge (Mean=0.73, $\mathrm{SD}=0.14$ ) and prevention-based knowledge (Mean=0.88, SD=0.15), level of symptoms based knowledge (Mean=0.49, $\mathrm{SD}=0.19$ ) is found to be low with respect to their mean and standard deviation. However, the overall level of knowledge (Mean=0.77, SD=0.11) found to be high. In relation to measured items, the knowledge level found to be poor in (i) persons with COVID-19 cannot infect the virus to others when, a fever is not present (Mean=0.2, $\mathrm{SD}=0.40$ ) (ii) Unlike the common cold, stuffy nose, runny nose and sneezing are less common in persons infected with the COVID-19 virus (Mean=0.41, $\mathrm{SD}=0.49$ ) and (iii) anti-malarial drugs are being used for treating the patients with COVID-19 (Mean=0.43, $\quad \mathrm{SD}=0.05)$. Additionally, the knowledge of the participants found to comparatively high in (i) The main clinical symptoms of COVID-19 are fever, fatigue, dry cough, and myalgia
(Mean=0.96, $\mathrm{SD}=0.18$ ), (ii) Isolation and treatment of people who are infected with the COVID-19 virus are effective ways to reduce the spread of the virus (Mean=0.96, $S D=20$ ), (iii) People who have contact with someone infected with the COVID-19 virus should be immediately isolated in a proper place. In general, the observation period is 14 days (Mean=0.95, SD=0.21).

Table 2 shows that the level of agreed on all measured items found to be high because the frequency on agree is ranged from $70.6 \%$ to $92.7 \%$. Hence the attitude of the persons towards COVID-19 is good and agreed that Nepal will success to control the disease and careful on the increment of immunity power. Table 3 shows that the participants are highly careful about COVID-19. Almost of them have a practice of living safely and the majority of the participants are using mask (94.5\%), manage social distance (91.7\%) and using sanitizer/and soap (94\%). Additionally, the majority of the respondents are careful on improving their immunity powers (88.5\%). The result also shows that the digital resource users are careful about COVID-19. In Table 4, it can be seen that significant results found in awareness and prevention-based knowledge with respect to the educational background of the respondent and in information related knowledge with respect to daily using time of social media. Additionally, the participants with management background have less mean rank in awareness (72.58) and prevention (69.61) is found to be poor as compared to those with other stream of education. Also, the mean ranks of the participants who use social media greater than 6 hours per day are comparatively low with respect to awareness-based knowledge. In other cases, the result is insignificant at $95 \%$ level of confidences [table 4]. 
Table 2: Questionnaire of attitude and participant's responses towards COVID-19 (n=218)

\begin{tabular}{llccc}
\hline SN & Statements & \multicolumn{3}{c}{ Responses in percentage } \\
\cline { 3 - 5 } & & Agree & Disagree & I don't know \\
\hline 1. & Nepal can win the battle against the COVID-19 virus. & 70.6 & 16.5 & 12.8 \\
2. & Improved immunity can protect against the COVID-19 virus. & 92.7 & 4.6 & 2.8 \\
3. & Lockdown period should be extended to control the COVID -19. & 73.9 & 21.6 & 4.6 \\
\hline
\end{tabular}

Table 3: Questionnaire of practice and participant's responses towards COVID-19(n=218)

\begin{tabular}{llccc}
\hline SN & Statements & \multicolumn{2}{c}{ Responses in Percentages } \\
\cline { 3 - 4 } & & No & Yes & Not always \\
\hline 1. & In recent days, have you moved outside of your residence, to any crowded place? & 80.7 & 10.6 & 8.7 \\
2. & Do you usea mask for going outdoors during the COVID-19 pandemic? & 2.8 & 94.5 & 2.8 \\
3. & Do you maintain social distancing during the COVID-19 pandemic? & 6.4 & 91.7 & 1.8 \\
4. & Do you use sanitizer/Soap water to clean your hands each time after you come from & 2.3 & 94 & 3.7 \\
& outdoors during the COVID-19 pandemic? & 5.5 & 88.5 & 6.0 \\
5. & Do you care about improving your immune system these days? & &
\end{tabular}

Table 4: Correlation of demographic characteristics and the knowledge (symptoms, awareness and prevention) towards COVID-19 based on univariate analysis $(n=218)$

\begin{tabular}{|c|c|c|c|c|c|c|c|}
\hline \multirow[t]{2}{*}{ Socio-demographic Characteristics } & \multirow[t]{2}{*}{$\begin{array}{l}\text { Frequency } \\
(\%)\end{array}$} & \multicolumn{2}{|c|}{$\begin{array}{l}\text { Symptoms based } \\
\text { Knowledge }\end{array}$} & \multicolumn{2}{|c|}{$\begin{array}{l}\text { Awareness based } \\
\text { knowledge }\end{array}$} & \multicolumn{2}{|c|}{$\begin{array}{l}\text { Prevention based } \\
\text { knowledge }\end{array}$} \\
\hline & & $\begin{array}{l}\text { Mean } \\
\text { Ranks }\end{array}$ & P-value & $\begin{array}{l}\text { Mean } \\
\text { Ranks }\end{array}$ & P-value & $\begin{array}{l}\text { Mean } \\
\text { Ranks }\end{array}$ & P-value \\
\hline \multicolumn{8}{|l|}{ Age } \\
\hline Less than 25 years & $50(22.9)$ & 104.52 & 0.69 & 101.62 & 0.76 & 104.04 & 0.82 \\
\hline $26-35$ years & $94(43.1)$ & 107.55 & & 110.58 & & 112.96 & \\
\hline $36-45$ years & $55(25.2)$ & 117.34 & & 114.06 & & 110.15 & \\
\hline More than 45 years & $19(8.7)$ & 109.55 & & 111.68 & & 104.87 & \\
\hline \multicolumn{8}{|l|}{ Gender } \\
\hline Female & $46(21.1)$ & 103.96 & 0.47 & 113.75 & 0.60 & 107.37 & 0.78 \\
\hline Male & $172(78.9)$ & 110.98 & & 108.36 & & 110.07 & \\
\hline \multicolumn{8}{|l|}{ Educational background } \\
\hline Education & $88(40.4)$ & 114.66 & 0.74 & 106.85 & $0.05^{*}$ & 116.06 & $0.05^{*}$ \\
\hline Humanities & $37(17.0)$ & 97.82 & & 112.46 & & 108.26 & \\
\hline Management & $18(8.3)$ & 102.00 & & 72.58 & & 69.61 & \\
\hline Medical & $22(10.1)$ & 107.32 & & 119.45 & & 120.98 & \\
\hline Science & $33(15.1)$ & 111.00 & & 129.18 & & 104.56 & \\
\hline Others & $20(9.2)$ & 115.05 & & 105.48 & & 114.35 & \\
\hline \multicolumn{8}{|l|}{ Job Role } \\
\hline Teaching & $136(62.4)$ & 115.15 & 0.13 & 108.39 & 0.90 & 112.72 & 0.57 \\
\hline Private Job & $26(11.9)$ & 92.31 & & 108.58 & & 104.63 & \\
\hline Students & $56(25.7)$ & 103.77 & & 112.62 & & 103.93 & \\
\hline \multicolumn{8}{|l|}{ Location of Permanent Resident } \\
\hline Province 1 & $30(13.8)$ & 101.98 & 0.20 & 108.47 & 0.76 & 82.22 & 0.11 \\
\hline Province 2 & $30(13.8)$ & 88.48 & & 98.05 & & 109.57 & \\
\hline Bagmati Province & $32(14.7)$ & 123.61 & & 108.34 & & 122.50 & \\
\hline Gandaki Province & $31(14.2)$ & 118.84 & & 113.15 & & 108.02 & \\
\hline Province 5 & $34(15.6)$ & 108.62 & & 120.47 & & 123.59 & \\
\hline KarnaliProvince & $30(13.8)$ & 118.18 & & 116.68 & & 110.95 & \\
\hline Sudur-Paschim Province & $31(14.2)$ & 105.77 & & 100.15 & & 107.05 & \\
\hline \multicolumn{8}{|l|}{ Time of using Social media } \\
\hline Less than 3 hours & $82(37.6)$ & 101.77 & 0.30 & 118.12 & $0.01^{*}$ & 112.46 & 0.63 \\
\hline 3-6 hours & $95(43.6)$ & 110.41 & & 114.26 & & 111.28 & \\
\hline 6-9 hours & $30(13.8)$ & 121.80 & & 77.77 & & 101.78 & \\
\hline More than 9 hours & $11(5.0)$ & 125.73 & & 90.68 & & 93.09 & \\
\hline
\end{tabular}


Table 5 shows that the significant result is found in knowledge and attitude about COVID-19 with respect to the educational background of participants whereas mean ranks are comparatively poor in relation to management background participants. Also, the result is significant in attitudes of participants with respect to the job role in favor of teachers and students because the mean ranks of participants engaged in a private job found to be low in comparison to others. However, Mann-Whitney $U$ and Kruskal Wallis $\mathrm{H}$ tests show insignificant at 95\% level of confidence in other mentioned cases.

\section{DISCUSSION}

Participants taking part in this survey had shown high-level of sensible knowledge (Mean=0.73, SD=0.11) towards COVID-19. Till date, no specific antiviral drug or vaccine for the virus has been reported and a complete clinical picture of COVID-19 is yet to be understood, however, participants responded satisfactory level (Mean $=0.49, \mathrm{SD}=0.19$ ) on symptoms-based knowledge. The range of correct answer rate of the participants was from $57.3 \%$ to $96.1 \%$, which is in accordance with a similar study done in Malaysia [13]. Similarly, level of knowledge is found to be in good level in awareness-based questionnaire,

Table 5: COVID-19 based knowledge, attitude and practices with respect to socio-demographic characteristics $(\mathbf{n}=\mathbf{2 1 8})$

\begin{tabular}{|c|c|c|c|c|c|c|c|}
\hline \multirow[t]{2}{*}{ Socio-demographic Characteristics } & \multirow{2}{*}{$\begin{array}{l}\text { Frequency } \\
\text { (\%) }\end{array}$} & \multicolumn{2}{|c|}{ Knowledge } & \multicolumn{2}{|l|}{ Attitude } & \multicolumn{2}{|c|}{ Practices } \\
\hline & & $\begin{array}{l}\text { Mean } \\
\text { Ranks }\end{array}$ & $\begin{array}{l}\mathrm{P}- \\
\text { value }\end{array}$ & $\begin{array}{l}\text { Mean } \\
\text { Ranks }\end{array}$ & $\begin{array}{l}\text { P- } \\
\text { value }\end{array}$ & $\begin{array}{l}\text { Mean } \\
\text { Ranks }\end{array}$ & $\begin{array}{l}\mathrm{P} \text { - } \\
\text { value }\end{array}$ \\
\hline \multicolumn{8}{|l|}{ Age } \\
\hline Less than 25 years & $50(22.9)$ & 100.14 & 0.64 & 102.31 & 0.75 & 99.95 & 0.10 \\
\hline $26-35$ years & $94(43.1)$ & 110.76 & & 111.38 & & 117.70 & \\
\hline $36-45$ years & $55(25.2)$ & 115.65 & & 110.08 & & 110.55 & \\
\hline More than 45 years & $19(8.7)$ & 110.11 & & 117.42 & & 91.00 & \\
\hline \multicolumn{8}{|l|}{ Gender } \\
\hline Female & $46(21.1)$ & 112.26 & 0.74 & 107.83 & 0.83 & 115.39 & 0.39 \\
\hline Male & $172(78.9)$ & 108.76 & & 109.95 & & 107.92 & \\
\hline \multicolumn{8}{|l|}{ Educational background } \\
\hline Education & $88(40.4)$ & 111.88 & $0.03^{*}$ & 115.96 & $0.03^{*}$ & 115.06 & 0.11 \\
\hline Humanities & $37(17.0)$ & 106.49 & & 102.50 & & 109.34 & \\
\hline Management & $18(8.3)$ & 62.78 & & 67.19 & & 75.03 & \\
\hline Medical & $22(10.1)$ & 121.82 & & 106.93 & & 109.20 & \\
\hline Science & $33(15.1)$ & 120.35 & & 119.62 & & 114.30 & \\
\hline Others & $20(9.2)$ & 115.23 & & 118.23 & & 108.78 & \\
\hline \multicolumn{8}{|l|}{ Job Role } \\
\hline Teaching & $136(62.4)$ & 111.87 & 0.60 & 115.67 & $0.04^{*}$ & 114.07 & 0.07 \\
\hline Private Job & $26(11.9)$ & 98.44 & & 84.62 & & 87.98 & \\
\hline Students & $56(25.7)$ & 108.88 & & 106.07 & & 108.40 & \\
\hline \multicolumn{8}{|l|}{ Location of Permanent Resident } \\
\hline Province 1 & $30(13.8)$ & 95.27 & 0.25 & 101.18 & 0.26 & 116.78 & 0.67 \\
\hline Province 2 & $30(13.8)$ & 95.28 & & 107.07 & & 103.00 & \\
\hline Bagmati Province & $32(14.7)$ & 117.86 & & 110.50 & & 117.53 & \\
\hline Gandaki Province & $31(14.2)$ & 111.31 & & 113.81 & & 104.53 & \\
\hline Province 5 & $34(15.6)$ & 124.65 & & 130.91 & & 110.06 & \\
\hline KarnaliProvince & $30(13.8)$ & 121.28 & & 106.80 & & 116.55 & \\
\hline Sudur-Paschim Province & $31(14.2)$ & 98.58 & & 93.69 & & 97.98 & \\
\hline \multicolumn{8}{|l|}{ Time of using Social media } \\
\hline Less than 3 hours & $82(37.6)$ & 113.16 & 0.17 & 119.54 & 0.07 & 112.35 & 0.10 \\
\hline $3-6$ hours & $95(43.6)$ & 114.60 & & 103.17 & & 113.88 & \\
\hline 6-9 hours & $30(13.8)$ & 87.17 & & 114.23 & & 87.37 & \\
\hline More than 9 hours & $11(5.0)$ & 99.09 & & 76.45 & & 110.77 & \\
\hline
\end{tabular}


Category-B, (Mean=0.73, SD=0.14) and prevention-based questionnaires, Category-C, (Mean=0.88, SD=0.15). The low correct answer rate was found in symptoms-based knowledge as compared to awareness and prevention-based knowledge which signifies that all the communication agencies, mass media including social media and the journalist should focus on symptom-based awareness programs. In addition, significant result was measured in awareness and prevention-based knowledge with education background of the participants and awareness-based knowledge with daily using time of social media in the socio-demographic information (table 5).

The present study found that the majority of participants held positive attitudes toward overcoming COVID-19 epidemic. The majority of them believe that improved immune system of their body could protect them against COVID-19. However, $16.5 \%$ of participants were not generally satisfied with the effort contributed by the Government of Nepal against the control of the virus. This is due to the inadequate health facilities, including the low number of tests, shortage of testing kits, and required Personal Protective Equipment (PPE) for the medical staff at its initial period. The results is in accordance with a similar study done in Nepal, where $78 \%$ of the participants have shown confidence level on control over COVID-19 [15]. The participants (73.9\%) also supported that the ongoing lockdown should be extended to control the transmission of the virus in the community and country. The significant difference was found in the attitude of participants with respect to educational background $(p=0.03)$ and their job role of the participants $(p=0.04)$ (table 5). This belief towards the control over the disease is because of the very low spreading rate of the virus in its initial phase in Nepal.

In the current study, most of the participants reported that they are following standard precautions as recommended by the WHO in order to avoid contamination by COVID-19 [15]. The emergence of COVID-19 caused increased demands for face masks, hand sanitizer, disinfectant spray and gloves. Nine people out of ten are using face masks and hand sanitizer when they moved outside, however the use of face masks was not normal in Nepalese society before this epidemic. The participants were avoided to go to the crowded place, even though they did not celebrate the New Year function dated 13 April 2020 Nepali calendar. Participants are strictly following the norms of social distancing in the crowded place, in the community and even in houses too. This higher level of good practice among participants is due to the exchange of information about COVID-19 via social media, newspapers, broadcasting media, mobile ring tones and governmental official web pages.

In summary, our finding suggests that social media users in Nepal have a relatively high level of knowledge, optimistic attitudes and appropriate practices towards COVID-19 during this rapid spreading period of this pandemic outbreak. It is worth noting that there was no significant difference among the mean of knowledge, attitude and practices with all socio-demographic variables except educational background and job role of participants. This is expected due to the government immediate action and wide coverage on media after the outbreak of COVID-19. However, our study is limited to only those participants who are involved in social media and have access of internet facility. As a result, there is a possibility of bias as underprivileged populations may not 
have been able to participate in the study. Likewise, our study is limited to a small sample size which accounts for it being statistically insignificant; nevertheless, it might not be the case in practice. A more systematic, inclusive sampling method is demanded to improve the representativeness and generalization of the findings.

\section{CONCLUSION}

The present study revealed good knowledge, an optimistic attitude and appropriate practice among social media users towards COVID-19 in Nepal. The significant results are reported on awareness and prevention-based knowledge with the education background of the participants. The attitude of participants towards COVID-19 is also significant with their educational background. Overall, the high level of practice among social media users reflects the wide exchange of knowledge through social media, newspapers, broadcasting media, mobile ring tones and governmental official web pages on COVID-19 pandemic. The findings of this study might prove as the baseline for planning awareness campaigns in the public level and implementing government efforts and plan for better containment of COVID-19.

\section{ACKNOWLEDGEMENTS}

We express heartfelt thanks to all the respondents who participated in this research and also thanks to all who shared the link of Google Form in social sites.

\section{REFERENCES}

1. WHO. WHO announces COVID-19 outbreak a pandemic. World health Organisation. World Health Organization; 2020.

2. Prasain S. Visit Nepal 2020 called off, finally. The Kathmandu Post. 2020 Mar;

3. Zhu N, Zhang D, Wang W, Li X, Yang B, Song J, et al. A Novel Coronavirus from Patients with Pneumonia in China, 2019. N Engl J Med. 2020;382(8):727-33.

4. Yin Y, Wunderink RG. MERS, SARS and other coronaviruses as causes of pneumonia. Respirology. 2018 Feb;23:130-7.

5. Leppard GG. Evaluation of electron microscope techniques for the description of aquatic colloids. Environ Part CRC Press . 2019;231-89.

6. Mishra VP, Paudel S, Twanabasu S, Thapa K, Kusma S. Ongoing COVID-19 pandemic: Current Status of Nepal. Eur J Med Sci. 20AD;1(2):81-4.

7. Pradhan TR. Nepal goes under lockdown for a week starting 6am Tuesday. The Kathmandu Post. 2020 Mar;

8. Thompson R. Correspondence coronavirus case in. Lancet Infect Dis. 2020;20(3):279-80.

9. Paudel A. Nepal reports its first Covid-19 death. The Kathmandu Post. 2020 May;

10. MoHP. Health Sector Response to COVID-19. Kathmandu; 2020.

11. Pradhan TR. Lockdown is officially eased, with private vehicles allowed on odd-even basis and shops to open. The Kathmandu Post. 2020 Jun;

12. Huck SW. Reading Statistics and Research. 6th ed. Boston: Pearson Education, Inc., publishing; 2012.

13. Azlan AA, Hamzah MR, Jen T, Id S, Hadi S, Id A. Public knowledge, attitudes and practices towards COVID-19: A cross-sectional study in. 2020;1-15.

14. Asraf H, Garima T, Singh BM, Ram R, Tripti RP. O R I G I N A L A RTICL E Knowledge, attitudes , and practices towards COVID-19 among Nepalese Residents: A quick online crosssectional survey. 2020;11(3).

15. UNN. COVID-19 Nepal: Preparedness and Response Plan (NPRP). Kathmandu; 2020. 